Article

\title{
The Educational Level of Rural Labor, Population Urbanization, and Sustainable Economic Growth in China
}

\author{
Shu Cao ${ }^{1}$, Nannan $\mathrm{Yu}^{1}$, Yang $\mathrm{Wu}^{2, *}$, Zihe Wang ${ }^{3}$ and Jianing $\mathrm{Mi}{ }^{1}$ \\ 1 School of Management, Harbin Institute of Technology, Harbin 150000, China; caoshu318@163.com (S.C.); \\ nyuhit@gmail.com (N.Y.); mijianing@hit.edu.cn (J.M.) \\ 2 School of Humanities and Social Sciences, Beijing Institute of Technology, Beijing 100081, China \\ 3 International Education Centre, Harbin Engineering University, Harbin 150001, China; \\ wangzihe_2019@163.com \\ * Correspondence: wu_yang@bit.edu.cn
}

Received: 3 May 2020; Accepted: 10 June 2020; Published: 15 June 2020

\begin{abstract}
Since the 1978 economic reform, China has undergone a historical process of rapid urbanization. Although this process has been recognized as a key factor in the development of sustainable growth in China, low quality rural labor continues to limit the effectiveness of the country's urbanization. Our study uses a spatial analysis framework to explore how the education level of rural laborers moderates the effect of urbanization on economic growth with provincial data collected from 1996 to 2015. Our results reveal that the influence of population urbanization on sustainable growth is mediated by the improvement of consumption capacity of urban dwellers and the industrial structural changes. The education level of rural laborers adjusts the urbanization's influence on the consumption capacity of residents, which further affects economic growth. Empirical evidence indicates that the educationally limited rural population negatively moderates the impact of urbanization on sustainable economic growth by restraining the consumption capacity of migrating rural labor. It is also found that in some provinces with less-qualified rural labor, such as Gansu, Yunnan and Qinghai, population urbanization has not contributed to a corresponding economic growth, indicating that these provinces may have undergone urbanization without growth. These findings suggest that basic education is critical to the growth of income and consumption capacities of rural labor when laborers are migrating to urban areas. To achieve a valid urbanization process and sustainable growth, state and local governments must improve the basic education scheme, especially the nine-year compulsory education in Chinese rural areas through public financial investment and policy support.
\end{abstract}

Keywords: education level; rural labor; population urbanization; sustainable growth; China

\section{Introduction}

Since economic reform began in 1978 and particularly since the mid-1990s, China has undergone rapid urbanization development, which has become an important engine of the country's economic post-industrialization growth. The urbanization rate in China grew from $17.92 \%$ in 1978 to $59.58 \%$ in 2017 [1]. "China Urbanization 2.0: Super Metropolis" released by Morgan Stanley, forecasts that urbanization rates in China will reach $75 \%$ by 2030 [2]. Both developed and developing countries have confirmed the positive impacts of urbanization on boosting domestic demand, supporting economic restructuring, and driving sustainable economic growth. Currently, China, which has a typical dual urban-rural structure, is undergoing a systemic economic transformation. Therefore, it is worth determining whether Chinese-style urbanization, characterized by urban population growth and rapid expansion of urban land, could effectively promote sustainable economic growth. On the one hand, 
land-centric urbanization is considered a more direct and shortsighted stimulus for economic growth. Local governments push spatial urbanization in the form of land expropriation, which can greatly increase government revenue, attract private investment, and enhance infrastructure investment. In this way, a local economy could have an impressive performance in a short period of time [3,4]. However, population urbanization cannot stimulate economic growth in a very short term as land urbanization does. The population urbanization may result in more long-term changes in sustainable growth.

Several studies have focused on the relationship between population urbanization and economic growth based on the experience of developed countries [5-9]. Generally, urbanization is always regarded as an outcome of economic growth, and it can fuel further growth when properly managed. Thus, many studies have confirmed a positive correlation between urbanization and economic development level [10-12]. Urbanization accumulates human capital for modern industry and service-industry fields $[13,14]$. With a growing population that is transitioning from rural to urban areas, a population urbanization process would not only improve the income and consumption capability for the new urban residents, but also provide a sufficient labor force for long-term growth and human capital accumulation [15]. Others have also conducted empirical studies on the relationship between China's population urbanization and economic growth. However, urbanization in China has unique features, due to its political conditions and historical process.

In many developed countries, urbanization rates and GDP have grown together without substantive government intervention. In some cases, market elements (such as technological innovation, and the evolution and increasing efficiency of productivity) have played important roles in the process of so-called 'parallel-urbanization', achieving high economic growth rate and a parallel increase in the degree of urbanization. Therefore, urbanization in many developed countries can be described as market-driven urbanization because it is rooted in individuals' decisions to move to urban centers under incentives provided by markets. While besides market-driven urbanization, the government-driven urbanization exists as well in China. Chinese local governments have been inclined to accelerate the pace of urbanization in a compelling way, forcing farmers to migrate into urban areas by paying compensation money to farmers who have lost their land. Both market-driven urbanization and government-driven urbanization work together on China's economy. However, whether such complex urbanization could drive sustainable growth is unclear.

Theoretically, urbanization can promote economic growth by transferring labor from rural areas to urban areas, which could improve labor productivity. From this perspective, the quality of the rural population that has moved to urban sectors determines the impact of urbanization on economic growth. As the largest developing country, China is also an agricultural powerhouse with a rural population of 900 million [1]. In 2017, the average years of education among rural laborers aged 15 to 64 was 8.25 years, and it is three years shorter than among the urban labor force [1]. In addition, less than $1.5 \%$ of rural laborers have a junior college level or higher education, and it is $17 \%$ lower than urban laborers [1]. As such, a large number of rural laborers are unable to complete the nine-year compulsory education in China. Whether these less-educated laborers could play a positive role in economic growth when they work in an urban sector is a topic worthy of discussion. Therefore, this paper aims to explore the effect of rural labor's educational level on China's urbanization effectiveness and determine a referable strategy of sustainable development for government policy and decisions.

\section{Literature Review and Research Hypothesis}

\subsection{Urbanization and Economic Growth}

The research on urbanization and economic growth is sparked by the development of two streams of literature-the urban-rural migration model in development economics and the endogenous economic growth model. According to the development economics literature [15], urbanization and the rapid expansion of cities are driven by two factors. On the one hand, rapid population growth leads to the scarcity of agricultural land, which pushes rural people without land to move to cities. 
On the other hand, a booming urban economy pulls the rural labor work in cities by providing higher earnings. Endogenous economic growth models are based on Ramsey-Cass-Koopmans's endogenous saving-rate model and apply knowledge (or human capital) spillovers to explain the positive effect of technological progress on economic growth [16]. However, new economic growth theory neglects the spatial concentration of economic activities led by knowledge spillovers and the effect of such spatial agglomeration on the acceleration of human capital accumulation. The former focuses on how economic growth affects the pattern of urbanization, while the latter focuses on how urbanization promotes economic growth efficiency [13]. These two questions comprise the focus of research on urbanization and economic growth.

Scholars have explored the relationship between urbanization levels and economic growth since 1965. Berry, a geographer, conducted empirical research by using the data of 95 countries, and the results showed a significant positive correlation between a country's urbanization rate and economic growth [12]. However, Lucas sparked research on urbanization and economic growth. Bertinelli and Black pointed out that the aggregation effect of urbanization development has emerged as an important engine driving economic growth, and the positive effect of urbanization on economic growth presents as a U-shape [14].

Differing from the evidence of developed countries, where urbanization can be described as market-based urbanization because it is rooted in individuals' decisions to move to urban centers under incentives provided by markets, China has undergone government-driven urbanization as well, and local governors have accelerated the pace of urbanization by forcing farmers to migrate into urban areas or changing the identification (hukou). The local governments expect the government-driven urbanization could lead to significant growth. Scholars have conducted many empirical studies on China, and they have generally concluded that a positive correlation exists between urbanization and economic growth [3,17-22]. For example, Wang and Xia provided an empirical analysis using the panel data of more than 600 cities in China and showed that urbanization is the accelerator for economic growth [3]. Shen and Jiang found that during the urbanization process, economic growth could be driven by the acceleration of human capital accumulation and industrial structure optimization [17]. Duan and An studied sample data sets from 1978 to 2006 and concluded that in the process of urbanization, the expansion of domestic demand converts to the main mechanism for regional economic growth [18]. Wei and Wang analyzed the impact of urbanization and related innovation on total factor productivity and found that urbanization can improve the efficiency of technological innovation, and such progress indirectly improves the total factor productivity [22]. In theoretical predictions, Nie et al. discussed the long- and short-term impact of population urbanization on economic growth and indicated that long-term impact is more obvious than short-term impact [21]. Although this previous literature has explored the relationship between urbanization and economic growth, a lack of study remains regarding the mechanism by which population urbanization affect economic growth.

Theoretically speaking, population urbanization could make an impact on sustainable regional growth in several ways.

First, the increase in the population urbanization rate could improve consumption by the rural population affected by the urbanization process. Urban residents' disposable income is generally higher than that of rural residents. Therefore, individuals who move from rural areas to cities obtain higher income. According to the economic theory that income affects consumption, a higher income will boost consumer demand [15]. In other words, the income effect of an urban population increases consumer demand. However, the population proportion in urban and rural areas has changed because of population urbanization. Trading in urban areas promotes the consumption potential of individuals who shift from rural areas to urban areas, which further expands consumer demand [20]. Thus, the structural effect of the urban population also unleashes the potential of consumer demand [23].

Based on the above-mentioned analysis, we propose the following hypothesis: 
Hypothesis 1. Population urbanization has a positive effect on economic growth by improving urban residents' consumption capacity.

Secondly, the improvement of population urbanization could help optimize the industrial structure that stimulates sustainable growth. With the development of population urbanization, surplus young laborers shift from rural to urban areas. At first, the decline of the rural population can optimize primary industries and facilitate the non-agricultural industry, which promotes the proportion of secondary and tertiary industries in a country/region's national economy. In addition, the urban population increase enhances the development of the secondary and tertiary industries, and thus, accelerates the upgrade and optimization of the industrial structure. Structuralists believe that structural transformation is the accelerator for economic growth [21]. Therefore, population urbanization drives the global economy forward by initially promoting industrial structure optimization and indirectly boosting a country/region's economic growth. Based on the above-mentioned analysis, we propose the following hypothesis:

Hypothesis 2. Population urbanization has a positive effect on economic growth by optimizing the industry structure.

Finally, increasing population urbanization could facilitate technology innovation, which drives long-term growth. Urban aggregation of peoples, enterprises, and industries contributes to a diversified environment, providing a platform for industries from different fields to communicate, and the emergence of new knowledge, technologies, and industries. In addition, cities are blessed with good educational infrastructure and access, which guarantees a rich stock of human capital. Cities are equipped with other infrastructure, such as information and communication, which is conducive to spreading new knowledge and technologies [22]. As a result, the urbanization process can accelerate the innovation and expansion of knowledge and technologies. Currently, technological innovation and spillover inject a strong impetus for economic development and social progress. Based on the above-mentioned analysis, we propose the following hypothesis:

Hypothesis 3. Population urbanization has a positive effect on economic growth by increasing technology innovation.

\subsection{Rural Education and the Effectiveness of Urbanization}

Increasing concerns about rural education in developing countries results from the growing need to transform rural populations into human capital. Education, as advocated by human capital theorists [24], helps a population acquire the technical abilities and professional knowledge required to earn higher wages and improve the productivity of the society. Developing rural education is therefore useful for enhancing the quality of life for rural dwellers [25], and it is also beneficial for the national economy and contributes solid benefits to the improvement of urbanization effectiveness [26]. Urbanization, at its initial stage, is the extremely dynamical complex process of withdrawing massive amounts of labor from rural agricultural activities and concentrating them in urban areas for industrial activities $[27,28]$. The benefits of urbanization will be limited if the rural labor migrating to the industrial sectors are less educated. From the perspective of labor supply, unqualified rural migrant workers can only engage in simple physical work, which contributes little to labor productivity improvement. From the perspective of labor demand, low-level jobs fail to bring higher income and rural laborers' consumption capabilities, and thus, do not effectively stimulate domestic demand [29]. Meanwhile, rural education is significant inferior urban education-The average years of education among rural laborers is three years shorter than among the urban labor force in 2017 [1]. The less qualified rural laborers will lead to lower productivity. This effect induced by the migrated rural labors will decline because their children have more opportunities to receive an education. However, the effect will not fade out in a short time. Given that the migrated workforce could only get a limited 
income, most workforce (first generation) may not afford the education expenditure for their children in urban areas. More importantly, there are still many farmers in China (58.97 million people) [1]. China still has a long way to achieve its population urbanization. Thus, the effect on growth will sustain for a relatively long time, which can be regarded as 'sustainable economic growth'.

Therefore, according to this analysis, we believe that the effect of urbanization on economic growth is less positive when rural educational levels are in lower stages. As such, we propose the following hypothesis:

Hypothesis 4. A rural population with limited education negatively moderates the impact of population urbanization on sustainable economic growth.

Considering the research hypotheses of the above-mentioned urbanization growth channels, we believe the rural labor with a low educational level could impede the effectiveness of urbanization by three channels. Thus, we put forward the following hypotheses:

Hypothesis 4a. The education level of rural labor will affect the population urbanization's impact on residents' consumption capacity.

Hypothesis $\mathbf{4 b}$. The education level of rural labor will affect the population urbanization's impact on industrial structure.

Hypothesis 4c. The education level of rural labor will affect the population urbanization's impact on technology innovation.

Figure 1 depicts our conceptual model. Our empirical setting is based on the Chinese economy-a leading emerging economy that has undergone rapid, government-led urbanization during the last several decades. To verify the proposed hypotheses, the empirical study will be detailed in the next section.

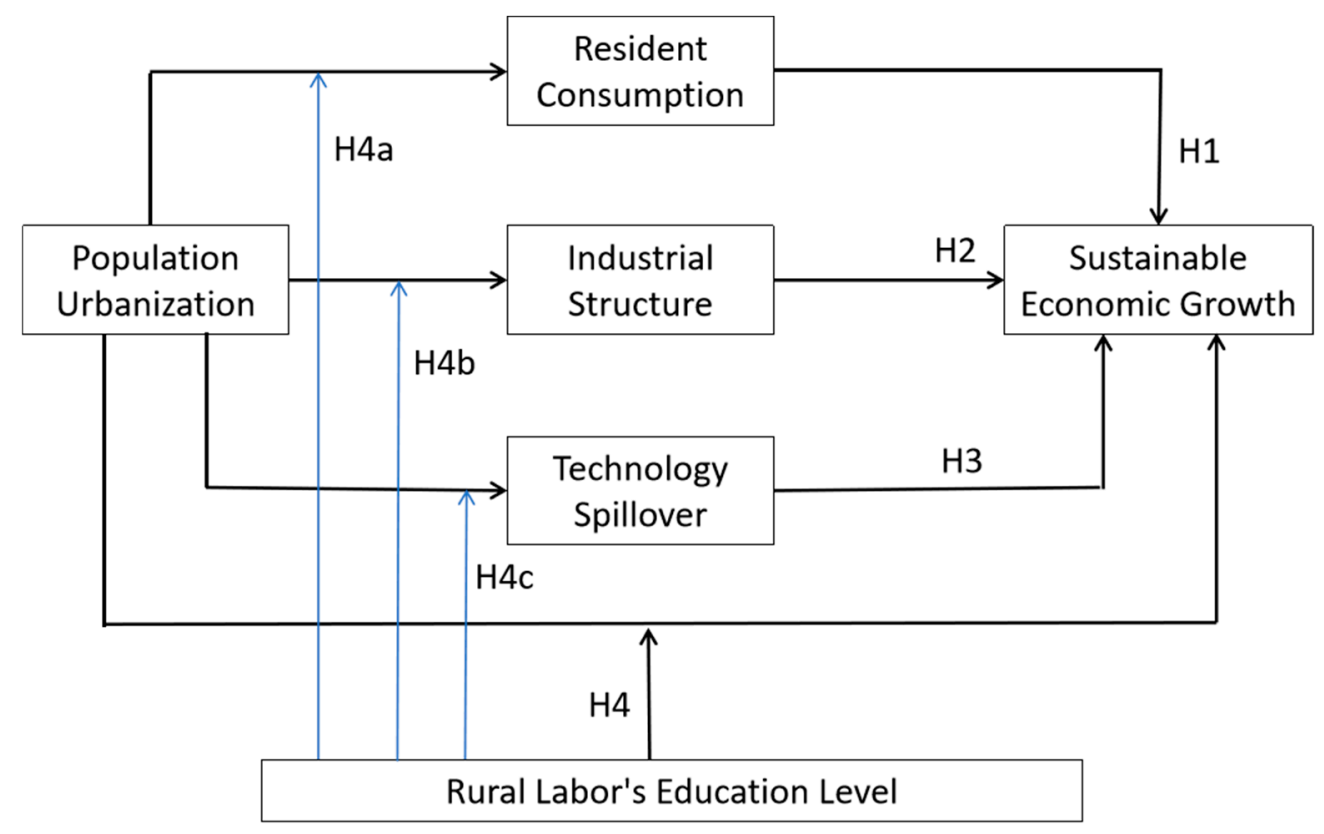

Figure 1. The conceptual model for this study. 


\section{Research Design}

\subsection{Modeling and Identification Strategy}

To fully consider the impact of spatial correlation on provincial economic growth, in this paper, we conducted empirical research with a spatial panel data model. We first identify how population urbanization affects economic growth and thereby verify $\mathrm{H} 1, \mathrm{H} 2$, and $\mathrm{H} 3$. However, the main purpose of our study is to determine the moderating effect of rural labor educational levels on urbanization effectiveness. Thus, after exploring the working channels of population urbanization, we pay special attention to testing the effect of rural labor educational levels on urbanization $(\mathrm{H} 4)$ and the mediating variables (H4a, H4b, H4c).

First, we establish an empirical model to identify how population urbanization affects economic growth on a spatial autocorrelation model, which is given as,

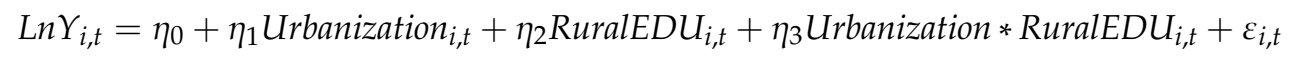

In this model, $Y$ represents the regional economic performance, which is measured by the actual per capita GDP of each province. Urbanization represents the population urbanization level. We use the proportion of the urban population at the end of the year in each province for representation. Consumption indexes the urban residents' consumption capacity. We measure the urban residents' consumption capacity by the final consumption expenditure of urban residents. We assume that urban residents' disposable income is generally higher than that of rural residents. Thus, individuals who move from rural areas to cities could obtain higher income. According to the economic theory that income affects consumption, a higher income will boost consumer demand. Moreover, easily trading in urban areas promotes the consumption potential of individuals who shift from rural areas to urban areas, which further expands consumer demand. That means if the rural labors move to the urban areas, their consumption potential could be unleashed, and the total urban consumption expenditure could increase because of the new migration. The consumption level of urban residents at 1996 constant price is used for representation.

Industry represents the industrial structure level, which is represented by the proportion of the secondary and tertiary industry output value in Gross Domestic Product. The output value is calculated at the current year's price in each province, while the index is calculated at the constant price. Innovation represents the innovation level. This model employs the patent authorization numbers in each province. $I$ and $t$ represent province and year, respectively, and $\varepsilon$ represents the error term. Here, we adopt a binary weight matrix to define $w_{i j}$. In other words, if only contiguous areas (with the same border) have a mutual effect, then 1 represents the two regions with the same borderline, 0 represents non-adjacent regions, and $\sum_{j=1}^{N} w_{i, j}=1$.

In our study, Equation (1) is a mediation model, which seeks to identify and explain the mechanism that underlies an observed relationship between urbanization rate and economic performance via the three mediating variables. In Equation (1), consumption capacity for residents (Consumption), industrial structure (Industry) and technology innovation (Innovation) are mediating variables that explain the indirect influence of independent variables on the dependent variables-i.e., how the urbanization rate affects economic growth. We report our identification strategies as follows. We first identify the effect of population urbanization on economic growth by adding mediating variables one by one, including the consumption capacity, industrial structure, and technology innovation. If $\beta_{1}$ significantly decreases after a mediating variable is added, and it is clearly shown that such a variable can partly explain the indirect influence of independent variables on dependent variables. This is what we are aiming for-i.e., if the new added mediating variable is successful, it is the working channel of urbanization on growth. 
After identifying the growth effect of population urbanization, we can then verify the effect of the rural labor education level on urbanization effectiveness, assuming that economic growth is a result of urbanization. When we introduce the element of the rural labor educational level into our model as a moderating variable, we should normalize the model, and the overall moderating effect of rural labor education can be pressed as follows:

$$
\operatorname{Ln} Y_{i, t}=\eta_{0}+\eta_{1} \text { Urbanization }_{i, t}+\eta_{2} \text { RuralEDU }_{i, t}+\eta_{3} \text { Urbanization } \text { RuralED }_{i, t}+\varepsilon_{i, t}
$$

Equation (2) aims to identify the direct effect of moderating variable. Here, RuralEDU indexes the educational level of rural labor and other variables are defined as previously discussed. If the value of $\eta_{3}$ is significant, the level of rural labor education can affect the effectiveness of urbanization. For example, if $\eta_{3}>0$, the effect of Urbanization on PGDP will increase with Rural-EDU value rising. If the opposite case happens-i.e., $\eta_{3}<0$ - such an effect will decrease as Rural-EDU value increases. However, if the value of $\eta 3$ is insignificant, no direct moderating effect will occur in our predictions. We then further test the moderated mediation, known as conditional indirect effects, occurs when the treatment effect of an independent variable $A$ (population urbanization) on an outcome variable $C$ (economic growth) via a mediator variable B (consumption, industry or innovation) differs depending on levels of a moderator variable $\mathrm{D}$ (rural education). The moderated mediation in our study is the indirect effect of Rural-EDU explained by mediating variables can be written as,

$$
\begin{gathered}
\text { Mediation }_{i, t}=\lambda_{0}+\lambda_{1} \text { Urbanization }_{i, t}+\lambda_{2} \text { RuralEDU }_{i, t}+\lambda_{3} \text { Urbanization }^{*} \text { RuralED }_{i, t}+\varepsilon_{i, t} \\
\begin{aligned}
{\text { LnY } Y_{i, t}=r_{0}+r_{1} \text { Urbanization }_{i, t}}+r_{2} \text { RuralEDU }_{i, t}+r_{3} \text { Urbanization } * \text { RuralEDU }_{i, t}+r_{4} \text { Mediation }_{i, t} \\
+r_{5} \text { Mediation }^{*} \text { RuralEDU }_{i, t}+\varepsilon_{i, t}
\end{aligned}
\end{gathered}
$$

Equations (3) and (4) aim to explore the indirect effect of moderating variable. Here, Mediation indexes the valid mediating variables, which refers to several working paths of urbanization on economic growth that have been previously identified, such as the consumption capacity of urban residents, the industrial structure, and technological innovation. If $\gamma_{3}$ and $\lambda_{3}$ are both significant, the moderating variables will then affect the relationship between the explanatory variables and the mediating variables. In another situation, if the values of $\gamma_{3}$ and $\lambda_{5}$ are significant, the moderating variables will affect the relationship between the mediating variables and the explained variables. Briefly, this work involves the method previously described to identify how the rural labor educational level affects urbanization effectiveness by mediating variables.

\subsection{Data Collection}

The urbanization process in China has developed rapidly since economic reform, especially after the 1990s. Thus, we choose the period of 1996-2015 as a sample observation period, during which most urbanization processes took place. Based on the data availability, the selected samples include data collected from 28 provincial regions on Mainland China, with the exception of Tibet, Xinjiang, and Hainan. As a panel dataset, the total number of observation is 560 for each variable. All of the reference data sets were primarily obtained from the China Statistical Yearbook, the China Science and Technology Statistical Yearbook, and the China Rural Statistical Yearbook. In addition, the data sets have been published on the National Bureau of Statistics website. We calculated some descriptive statistics on the relevant variables in Table 1.

In order to identify the rationality of spatial regression, we examine the Moran's I index of $L n(P G D P)$ Figure 2 presents the results. All the coefficients of spatial autocorrelation are positive at a $1 \%$ significance, which proves that the level of economic development in each region cluster in space. Using the traditional method without considering the spatial relationship would lead to biased regression coefficients. Thus, we develop our model in a spatial context, as shown in Equation (1). 
Table 1. Descriptive statistics.

\begin{tabular}{|c|c|c|c|c|c|c|}
\hline Variables & Measurement & Observations & Mean & Std.Dev & Min & Max \\
\hline GDP per capita $(P G D P)$ & $\begin{array}{l}\text { Total GDP in one province/total } \\
\text { population (yuan) }\end{array}$ & 560 & $22,294.78$ & $19,701.38$ & 2199 & 105,231 \\
\hline $\begin{array}{l}\text { Urbanization Rate } \\
\text { (Urbanization) }\end{array}$ & $\begin{array}{l}\text { Urbanization population/total } \\
\text { population }(\%)\end{array}$ & 560 & 0.445 & 0.167 & 0.140 & 0.896 \\
\hline $\begin{array}{l}\text { Consumption Ability } \\
\quad \text { (Consumption) }\end{array}$ & $\begin{array}{l}\text { Total consumption of urban } \\
\text { residents/total urban population } \\
\text { (yuan) }\end{array}$ & 560 & 2303.43 & 2982.95 & 16.13 & $21,913.9$ \\
\hline $\begin{array}{l}\text { Industrial Structure } \\
\text { (Industry) }\end{array}$ & $\begin{array}{l}\text { Output value of the secondary and } \\
\text { Tertiary Industry/total GDP (\%) }\end{array}$ & 560 & 0.857 & 0.076 & 0.62 & 1 \\
\hline $\begin{array}{l}\text { Technology Innovation } \\
\text { (Innovation) }\end{array}$ & $\begin{array}{l}\text { The total number of patent in each } \\
\text { province }\end{array}$ & 560 & 5670.43 & $11,511.19$ & 512 & 126,936 \\
\hline $\begin{array}{l}\text { Rural Education } \\
\text { (Rural-EDU) }\end{array}$ & $\begin{array}{c}\text { The average schooling year of the } \\
\text { rural labor (year) }\end{array}$ & 560 & 7.714 & 1.264 & 2.228 & 10.582 \\
\hline
\end{tabular}
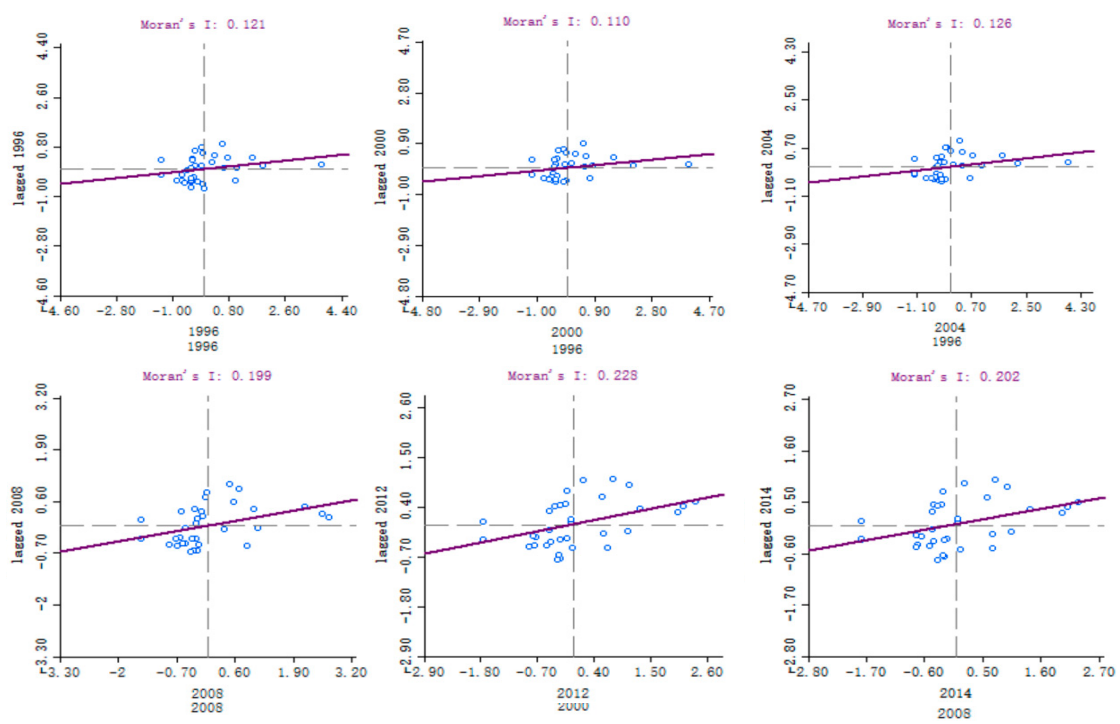

Figure 2. The results of spatial correlation tests.

\section{Empirical Results and Discussion}

\subsection{How Population Urbanization Drives Economic Growth}

Table 2 displays the regression results of Equation (1) based on SAR. As Table 2 shows, LM test results indicate that there exist spatial impacts in the basic model, and the estimators from the ordinary OLS without spatial factors are biased and overestimated. The results of the Wald test reject the null hypothesis that the spatial error model (SEM) are in favor of the spatial lag model (SAR). Thus, we choose the SAR finally to examine the effect of population urbanization on economic growth.

It can be clearly observed that the spatial correlation coefficients $\rho$ from Model I to Model V are all positive and at a $1 \%$ significance level. Thus, the economic development levels of neighboring provinces affect each other. That is to say, if we consider the spatial relationship in the model, we could predict more realistic results. In Model I, we can see that the coefficient of population urbanization is positive and passes the $1 \%$ significance level. The results indicate that population urbanization plays a positive role in China's economic growth, which is consistent with previous theoretical analyses and empirical tests $[4,20]$.

Next, we added the consumption capability of urban residents, industrial structure changes, and innovation abilities separately to Model II-Model IV. We found that adding the variable of residents' consumption capability reduces the effect of urbanization on economic growth (the sign of regression coefficient changes were not found to be at all significant in Model II), indicating that such a mediating 
variable is the way urbanization affects economic growth. After adding the industrial structure variable, the regression coefficient turns out to be much lower than the one in Model I, and therefore the industrial structure is a successful mediating variable as well. However, in Model IV, the coefficient of Urbanization does not significantly change-going from 0.84 to 1.79 . Thus, the variable of technology innovation is not a real mediating variable. The three variables (residents' consumption, industrial structure, and technology innovation) are simultaneously added to Model V, and the growth effect of urbanization is found insignificant. Hence, our chosen mediating variables are effective and can fully explain the growth effect caused by urbanization. These findings are partly consistent with previous studies on the case of China's [17,30-32].

Endogeneity may arise because it is not unreasonable to assume that the rural labors would love to move to urban centers for a higher income and better infrastructure induced by the booming manufacturing sectors. So as to ensure that results are not driven by reverse causation, we adopt a system Generalized Method of Moments (GMM) method for a robustness check, which combines a system of equations that include regressions in differences and regressions in levels. The Generalized Method of Moments (GMM) estimators are generally designed for situations with 'small T, large N'panels, meaning few time periods and many individuals, with independent variables that are not strictly exogenous, which perfectly fit our case. Here, sys-GMM regression takes the one-year lag variable of the dependent variable $(\operatorname{LnGDP}(-1))$ as the instrumental variable. The Sargan test for overidentifying restrictions is employed to assess whether the instruments are exogenous. We also present the regressions results in Table 2. The results are consistent with OLS estimations above. We found that adding the variables of residents' consumption capability and industrial structure reduced the effect of urbanization on economic growth, while there was very little change when we added technology innovation variable. Thus, the consumption capacity of urban residents and industrial structure are the valid mediating variables, whereas technology innovation is not. Our results are robust.

Based on these analyses, our Hypotheses 1 and 2 can be fully verified, however Hypothesis 3 has not been demonstrated. These findings make sense. On the one hand, a population moving from rural regions to cities will definitely obtain higher income and result in greater consumption demand in cities. Increasing consumption expenditure will drive the economy reciprocally. On the other hand, due to the decreasing rural population and increasing urban population, the secondary and tertiary industries will develop further, which accelerates the industrial structure optimization. However, it is worth noting that technology innovation is not a working path for population urbanization affecting economic growth. In other words, during the urbanization process in China, a large number of peasants do not behave more innovatively because of agglomeration after transferring to cities [33]. Thus, our empirical results show that China's population urbanization does not realize the growth by affecting technological innovation.

Table 2. Affecting channels of urbanization on economic growth.

\begin{tabular}{cccccc}
\hline \multicolumn{7}{c}{ OLS } \\
\hline & Model I & Model II & Model III & Model IV & Model V \\
\hline & LnPGDP & LnPGDP & LnPGDP & LnPGDP & LnPGDP \\
\hline \multirow{2}{*}{ Urbanization } & $1.739^{* * *}$ & 0.078 & $0.865^{* * *}$ & $1.687^{* * *}$ & -0.119 \\
& $(0.133)$ & $(0.138)$ & $(0.119)$ & $(0.140)$ & $(0.121)$ \\
\hline \multirow{2}{*}{ Consumption(H1) } & & $0.476^{* * *}$ & & & $0.369^{* * *}$ \\
& & $(0.026)$ & & & $(0.023)$ \\
\hline Industry & & $3.815^{* * *}$ & & $2.839^{* * *}$ \\
(H2) & & $(0.217)$ & & $(0.195)$ \\
\hline Innovation & & & 0.015 & -0.010 \\
(H3) & & & $(0.013)$ & $(0.009)$ \\
\hline
\end{tabular}


Table 2. Cont.

\begin{tabular}{|c|c|c|c|c|c|}
\hline \multicolumn{6}{|c|}{ OLS } \\
\hline & Model I & Model II & Model III & Model IV & Model V \\
\hline$\rho$ & $\begin{array}{c}0.776^{* * *} \\
(0.015)\end{array}$ & $\begin{array}{c}0.435^{* * * *} \\
(0.024)\end{array}$ & $\begin{array}{c}0.700^{* * * *} \\
(0.014)\end{array}$ & $\begin{array}{c}0.774^{* * * *} \\
(0.016)\end{array}$ & $\begin{array}{c}0.449^{* * * *} \\
(0.021)\end{array}$ \\
\hline Observations & 558 & 558 & 558 & 555 & 555 \\
\hline R-adj & 0.66 & 0.49 & 0.70 & 0.62 & 0.42 \\
\hline $\log \mathrm{L}$ & 210.25 & 361.94 & 337.95 & 210.96 & 451.75 \\
\hline LM spatial lag & $55.24(\mathrm{p}=0.00)$ & $56.25(\mathrm{p}=0.00)$ & $55.23(\mathrm{p}=0.00)$ & $55.64(\mathrm{p}=0.00)$ & $55.29(\mathrm{p}=0.00)$ \\
\hline $\begin{array}{l}\text { LM spatial } \\
\text { error }\end{array}$ & $36.51(\mathrm{p}=0.00)$ & $41.25(\mathrm{p}=0.00)$ & $37.46(\mathrm{p}=0.00)$ & $36.74(\mathrm{p}=0.00)$ & $40.35(\mathrm{p}=0.00)$ \\
\hline $\begin{array}{c}\text { Wald test } \\
\text { spatial error }\end{array}$ & $89.24(\mathrm{p}=0.00)$ & $88.35(\mathrm{p}-0.00)$ & $89.03(\mathrm{p}=0.00)$ & $89.71(\mathrm{p}=0.00)$ & $88.24(\mathrm{p}=0.00)$ \\
\hline Model & SAR & SAR & SAR & SAR & SAR \\
\hline \multicolumn{6}{|c|}{ SYS-GMM } \\
\hline & Model I & Model II & Model III & Model IV & Model V \\
\hline $\operatorname{LnGDP(-1)}$ & $\begin{array}{c}0.954^{* * *} \\
(0.006)\end{array}$ & $\begin{array}{c}0.823 * * * \\
(0.011)\end{array}$ & $\begin{array}{c}0.918^{* * *} \\
(0.006)\end{array}$ & $\begin{array}{c}0.953^{* * *} \\
(0.006)\end{array}$ & $\begin{array}{c}0.810^{* * *} \\
(0.012)\end{array}$ \\
\hline Urbanization & $\begin{array}{c}0.644^{* * *} \\
(0.056)\end{array}$ & $\begin{array}{c}0.482 * * * \\
(0.053)\end{array}$ & $\begin{array}{c}0.220 * * * \\
(0.064)\end{array}$ & $\begin{array}{c}0.624^{* * * *} \\
(0.056)\end{array}$ & $\begin{array}{c}0.120 \\
(0.062)\end{array}$ \\
\hline Consumption $(\mathrm{H} 1)$ & - & $\begin{array}{c}0.128^{* * * *} \\
(0.010)\end{array}$ & - & - & $\begin{array}{c}0.109^{* * * *} \\
(0.010)\end{array}$ \\
\hline $\begin{array}{l}\text { Industry } \\
\text { (H2) }\end{array}$ & - & - & $\begin{array}{c}1.783^{* * *} \\
(0.135)\end{array}$ & - & $\begin{array}{c}1.588^{* * *} \\
(0.128)\end{array}$ \\
\hline $\begin{array}{l}\text { Innovation } \\
(\mathrm{H} 3)\end{array}$ & - & - & & $\begin{array}{c}0.007 \\
(0.003)\end{array}$ & $\begin{array}{c}0.002 \\
(0.003)\end{array}$ \\
\hline Sargan test & $(0.17)$ & $(0.53)$ & $(0.35)$ & $(0.34)$ & $(0.51)$ \\
\hline Observations & 527 & 527 & 527 & 527 & 527 \\
\hline
\end{tabular}

Notes: 1. Robust standard errors are reported in parentheses; $2 .{ }^{* * *}$ significant at the $1 \%$ level; 3 . P-statistics are shown in the square brackets.

\subsection{Impact of Rural Education on Urbanization Effectiveness}

After identifying the working channels of population urbanization on growth, we test how rural education affects the effectiveness of urbanization.

We first examine the overall moderating effect of the rural educational level on economic growth. The results of Model VI in Table 3 show that the rural educational level does not make an overall moderating effect, because the coefficient of the interaction term between population urbanization and the educational level of rural labor (Urbanization*Rural-EDU) is insignificant. We then test the moderating effect of the rural labor educational level on the mediating variables, which were verified in Section 4.1. Based on the above-mentioned empirical results, we believe that the consumption capability of urban residents and the industrial structure changes are the true mediating variables and appear to be the working channels of urbanization on growth. Therefore, we test how the rural educational level affects the relationship between the consumption level of urban residents and the industrial structure changes and economic growth. In Table 3, it is noted that the coefficient of interaction term (Urbanization*Rural-EDU) is significantly positive in Model VII and Model VIII, while the coefficient of interaction term (Consumption*Rural-EDU) is not significant. In Section 3, we introduce that if $\gamma_{3}$ (Urbanization*Rural-EDU in Model VII) and $\lambda_{3}$ (Urbanization*Rural-EDU in Model VIII) are both significant, the moderating variables will then affect the relationship between the explanatory variables and the mediating variables. Thus, the rural educational level will affect the relationship between urbanization and residents' consumption capability and further make an impact on sustainable growth. Therefore, H4a can be verified. This finding is new and very interesting. If government-driven 
urbanization forces rural laborers lacking sufficient education to the cities, the unqualified rural laborers will not earn better jobs and higher income [34,35]. Therefore, as new urban residents, they have a very limited consumption capability that does not stimulate higher economic growth.

However, when we take into consideration another mediating variable (industrial structure), the coefficient of interaction term (Urbanization*Rural-EDU) is significantly negative in Model IX, but it is not significant in Model X. Therefore, it is reasonable to state that the rural education level does not affect the impact of industrial structure on urbanization. The possible reason is that it is the function of the government, not a free market adjustment, that drives industrial structural change in China. A larger investment encouraged by the government in the industrial sector expands the scale of production, thereby providing more jobs and attracting more rural surplus laborers to secondary and tertiary industries [36]. However, we note that the quality of the rural labor force plays a limited role in this process.

Table 3. Moderated effect of rural labor education on urbanization effectiveness.

\begin{tabular}{|c|c|c|c|c|c|}
\hline & Model VI & Model VII & Model VIII & Model IX & Model X \\
\hline & $\operatorname{Ln}(P G D P)$ & Consumption & $\begin{array}{c}\operatorname{Ln}(P G D P) \\
(\mathrm{H} 4 \mathrm{a})\end{array}$ & Industry & $\begin{array}{c}\operatorname{Ln}(P G D P) \\
(\mathrm{H} 4 \mathrm{~b})\end{array}$ \\
\hline Urbanization & $\begin{array}{c}3.455 * * * \\
(0.932)\end{array}$ & $\begin{array}{c}0.782 \\
(0.909)\end{array}$ & $\begin{array}{c}0.316 \\
(0.942)\end{array}$ & $\begin{array}{c}0.845^{* * *} \\
(0.069)\end{array}$ & $\begin{array}{l}-1.840 \\
(2.806) \\
\end{array}$ \\
\hline Rural-EDU & $\begin{array}{c}0.598 * * * \\
(0.066)\end{array}$ & $\begin{array}{c}0.498^{* * *} \\
(0.064)\end{array}$ & $\begin{array}{l}-0.018 \\
(0.046)\end{array}$ & $\begin{array}{c}0.063^{* * *} \\
(0.005)\end{array}$ & $\begin{array}{l}-0.230 \\
(0.266)\end{array}$ \\
\hline Urbanization*Rural-EDU & $\begin{array}{c}0.142 \\
(0.114)\end{array}$ & $\begin{array}{c}0.607^{* * *} \\
(0.111)\end{array}$ & $\begin{array}{l}0.171^{*} \\
(0.122)\end{array}$ & $\begin{array}{c}-0.077^{* * *} \\
(0.021)\end{array}$ & $\begin{array}{c}0.544 \\
(0.356)\end{array}$ \\
\hline Consumption & - & - & $\begin{array}{c}0.977^{* * *} \\
(0.101)\end{array}$ & - & - \\
\hline Consumption*Rural-EDU & - & - & $\begin{array}{l}-0.031 \\
(0.012)\end{array}$ & - & - \\
\hline Industry & - & - & - & - & $\begin{array}{l}4.507^{*} \\
(1.922)\end{array}$ \\
\hline Industry*Rural-EDU & - & - & - & - & $\begin{array}{c}0.509 \\
(0.353)\end{array}$ \\
\hline Constant & $\begin{array}{c}2.994^{* * *} \\
(0.447)\end{array}$ & $\begin{array}{c}0.673 \\
(0.434)\end{array}$ & $\begin{array}{c}3.896^{* * *} \\
(0.351)\end{array}$ & $\begin{array}{c}0.269^{* * *} \\
(0.033)\end{array}$ & $\begin{array}{l}3.056^{* *} \\
(1.068)\end{array}$ \\
\hline MODEL & Fixed & Fixed & Random & Fixed & Fixed \\
\hline Observations & 558 & 558 & 558 & 558 & 558 \\
\hline R-adj & 0.57 & 0.50 & 0.65 & 0.37 & 0.67 \\
\hline
\end{tabular}

Notes: 1 . Robust standard errors are reported in parentheses; $2 .{ }^{*}$ significant at the $10 \%$ level; ${ }^{* *}$ significant at the $5 \%$ level and ${ }^{* * *}$ significant at the $1 \%$ level.

Based on the above-mentioned analysis, we can conclude $\mathrm{H} 1$ and $\mathrm{H} 2$ have been directly verified while $\mathrm{H} 4$ and $\mathrm{H} 4 \mathrm{a}$ can be indirectly verified. Thus, population urbanization has a positive effect on economic growth by improving urban residents' consumption and optimizing industry structure. More important, the benefits of urbanization will be limited if the rural laborers migrating to industrial sectors are less educated, as they can only engage in simple physical work and fail to obtain higher incomes and consumption capabilities, which does not effectively stimulate domestic demand [37]. Thus, we can summarize that a rural population with limited education negatively moderates the effect of urbanization on sustainable economic growth.

\subsection{Population Urbanization Without Economic Growth}

Since economic reform in 1978, China has undergone a fast process of rapid urbanization. Until now, urbanization has been recognized as a key factor in the process of China's sustainable development. Our empirical findings explore the working channels of urbanization on long-term 
economic growth and restraining factors in its effectiveness. Some Chinese provinces may experience the urbanization process without growth because of rural laborers' educational levels. Figure 3 (from our previous study) shows the urbanization rate and growth rate by province, and it can be seen that significant differences exist among the 31 surveyed provinces. Some exhibit a positive relationship between the urbanization rate and growth, while others conform more to the attributes of urbanization without growth.

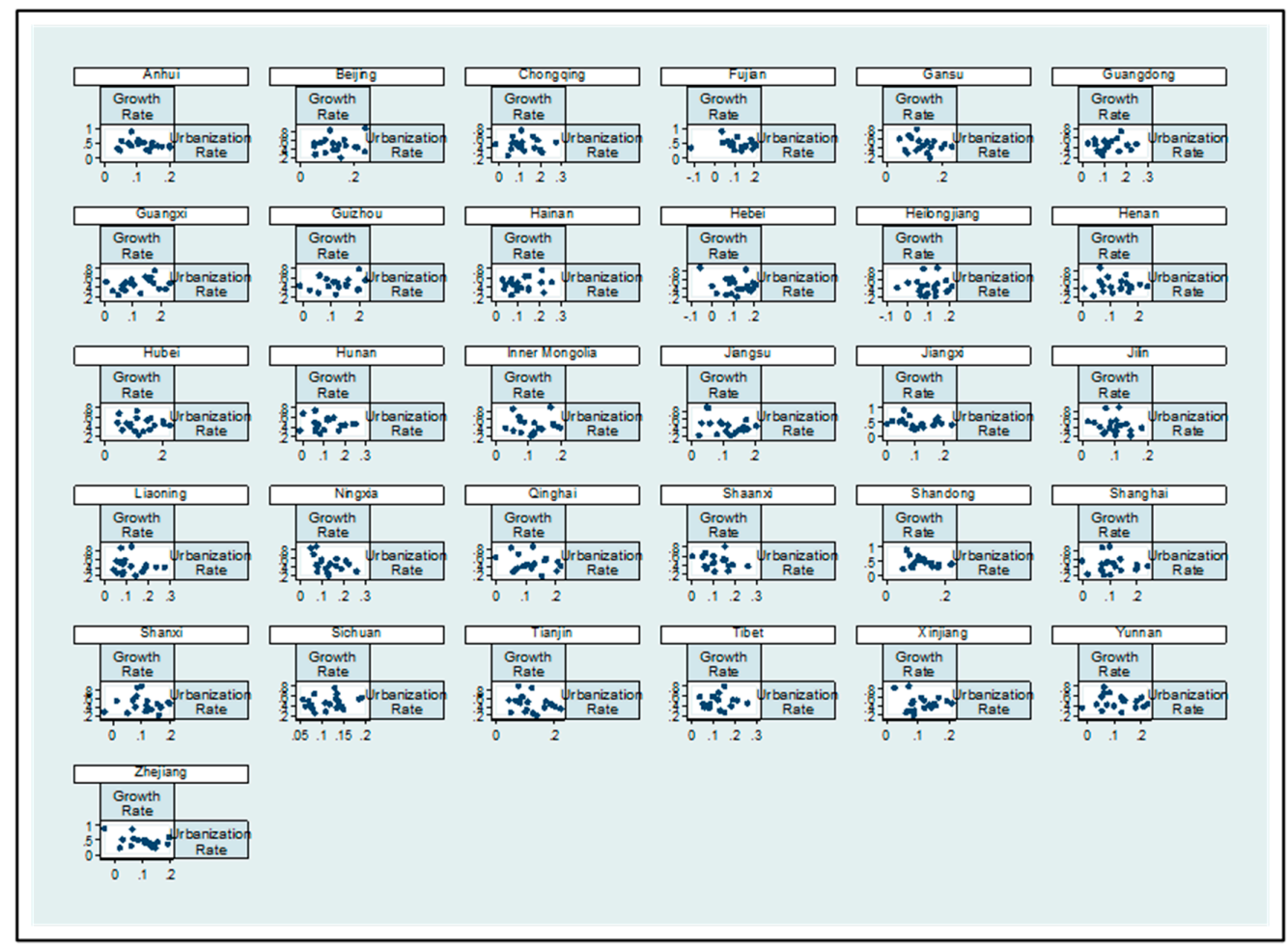

Figure 3. Urbanization rate and growth rate by province.

It is noticeable, however, that the provinces with ineffective urbanization have underdeveloped education levels, such as Gansu (6.45 years), Yunnan (6.48 years), Ningxia (6.47 years) and Qinghai (5.57 years). In the urbanization process of these provinces, rural laborers moving to cities have only received an average of six years of education or just the primary education stage. As such, their effect on local economic growth is very limited. In provinces with highly effective urbanization, such as Beijing (9.89 years), Liaoning (8.53 years), Hebei (8.38 years), and Heilongjiang (8.19 years), the average educational level of rural laborers is at a relatively high level-i.e., a complete or partially completely junior high school education. This result also confirms the rationality of our empirical research conclusion.

\section{Conclusions}

This paper theoretically and empirically highlights the moderating effect of rural labor educational levels on the growth effects of urbanization. We first identify the influence channels of population urbanization on sustainable growth in China, taking urban residents' consumption capacity, industrial structure, and technology innovation as mediating variables. Then we attempt to verify the impact of rural labor education levels on urbanization effectiveness by testing the moderated mediation.

The main conclusions based on our empirical study are as follows:

First, the influence of population urbanization on sustainable growth is mediated by the improvement of urban residents' consumption capability and industrial structural change. Moreover, 
our analysis reveals that the improvement of urban residents' consumption capacity is the main driver of economic growth caused by population urbanization.

Second, although it is generally believed that urbanization is an important factor in promoting sustainable economic growth, the level of rural laborers' education reduces urbanization efficiency by restraining urban residents' consumption capability. Our findings suggest that when rural laborers only receive limited education, population urbanization contributes little to the consumption capacity of urban residents. This kind of population urbanization would not lead to sustainable economic growth.

Third, some provinces (such as Gansu, Yunnan, and Qinghai), in which the average educational levels of rural laborers is very low, population urbanization has not contributed to a corresponding economic growth. The analysis suggests that these provinces have experienced urbanization without economic growth.

To conclude, this study attempts to fill a research gap by proposing a constraint factor (the educational level of rural laborer) on the link between population urbanization and sustainable growth. Our findings indicate that basic education is crucial to the growth of income and consumption capacity of rural laborers when they move to urban areas. In order to achieve a valid urbanization process and sustainable growth, state and local governments must improve the basic education framework and in particular, the nine-year compulsory education in Chinese rural areas through public financial investment and policy support. These findings offer rich policy implications for other developing countries as well, since the invalid urbanization or over-urbanization, which is a serious problem in many developing countries.

Author Contributions: Conceptualization, S.C. and N.Y.; methodology, N.Y.; software, S.C. and Z.W.; investigation, S.C. and Y.W.; resources, Y.W. and Z.W.; data curation, Y.W. and Z.W.; writing-original draft preparation, S.C. and N.Y.; writing - review and editing, Y.W. and J.M.; supervision, J.M. and N.Y. All authors have read and agreed to the published version of the manuscript.

Funding: This research was funded by the National Science Foundation of China, grant number 71774016 and 71403067.

Conflicts of Interest: The authors declare no conflict of interest.

\section{References}

1. State Statistical Bureau (SSB). China Statistical Yearbook; China Statistical Publishing House: Beijing, China, 2018.

2. Economic Daily. China Economy Net. 2019. Available online: http://www.ce.cn/xwzx/gnsz/gdxw/201910/15/ t20191015_33352515.shtml (accessed on 6 May 2020).

3. Wang, X.L.; Xia, X.L. Optimizing the size of cities to promote economic growth. Econ. Res. 1999, 9, 22-29.

4. Xie, D. Why does China's population urbanization lag behind spatial urbanization: A perceptive of Chinese-style decentralization. J. Guangdong Univ. Financ. Econ. 2016, 91-101.

5. Fay, M.; Opal, C. Urbanization Without Growth: A Not So Uncommon Phenomenon. 2000. Available online: http://documents.Worldbank.org/curated/en/287181468741917609/12252232220041117142056/additional/ multi-page.pdf (accessed on 6 May 2020).

6. UN, Department of Economic and Social Affairs, Population Facts. [EB/OL]. Available online: http: //www.un.org/esa/population/publications/WUP2005/2005wup.htm,2010-12-18 (accessed on 30 May 2020).

7. Ciccone, A.; Hall, R.E. Productivity and the Density of Economic Activity. Am. Econ. Rev. 1996, 86, 1.

8. Henderson, J. The Effects of Urban Concentration on Economic Growth. NBER Working Papers with Number7503. 2000. Available online: https://www.nber.org/papers/w7503.pdf (accessed on 12 June 2020).

9. Alberto, F.; Edward, A. Trade and Circuses:Explaining Urban Giants. Q. J. Econ. 1995, 110, 1.

10. Tian, X.Y. Warning against the "Latin American trap" in population urbanization. Macroecon. Res. 2006, 2, $12-17$.

11. Gao, Q.; Dong, Q.J; Shi, L. The process, characteristics, experience and enlightenment of rural urbanization in Brazil. World Agric. 2006, 4, 36-38.

12. Berry, B.J. Internal structure of the city. Law Contemp. Probl. 1965, 30, 111-119. [CrossRef]

13. Black, D.; Henderson, J.V. A theory of urban growth. J. Political Econ. 1999, 107, 252-284. [CrossRef] 
14. Bertinelli, L.; Black, D. Urbanization and growth. J. Urban Econ. 2004, 56, 81-98. [CrossRef]

15. Lucas, R.E. On the mechanics of economic development. J. Monet. Econ. 1988, 49, 783-792. [CrossRef]

16. Romer, P.M. Increasing returns and Long-Run Growth. J. Political Econ. 1986, 94, 1002-1037. [CrossRef]

17. Shen, K.R.; Jiang, R. An empirical study on the influence mechanism of urbanization on economic growth in China. Stat. Res. 2007, 6, 9-15.

18. Duan, R.J.; An, H.S. Econometric analysis of the relationship between urbanization and economic growth in China. Explor. Econ. Probl. 2009, 3, 26-30.

19. Lv, J. Spatial econometric analysis of urbanization driving economic growth: 2000-2009. Shanghai Econ. Res. 2011, 5, 3-15.

20. Nie, H.L.; Han, Y.; Qian, L. A comparative study of population urbanization and economic growth dynamics in China based on panel data. Soft Sci. 2012, 5, 27-31.

21. Shen, J.; Feng, Z.; Wong, K.Y. Dual-track urbanization in a transitional economy: The case of Pearl River Delta in South China. Habitat Int. 2016, 30, 690-705. [CrossRef]

22. Wei, X.H.; Wang, Y.L. Urbanization, innovation, and total factor productivity growth-Empirical research based on inter-provincial panel data. Financ. Sci. 2010, 3, 69-76.

23. Liu, H.L. Population urbanization, urban-rural income gap and consumer demand-An empirical analysis based on inter-provincial panel data. Popul. Econ. 2013, 6, 63-70.

24. Schultz, T.W. Investment in human beings. J. Political Econ. 1962, 72, 5.

25. Atchoarena, D.; Gasperini, L. Education for rural development: Towards new policy responses. Int. Inst. Educ. Plan. (IIEP) Unesco 2003, 25, 180-181.

26. Forget, E. A tale of two communities: Fighting poverty in the great society (1964-68). Hist. Political Econ. 2011, 43, 199-223. [CrossRef]

27. Champion, T. Urbanization, Suburbanization, Counter-Urbanization and Re-Urbanization. Handb. Urban Stud. 2001, 143-160.

28. Holden, L.; Biddle, J. The introduction of human capital theory into education policy in the United States. Hist. Political Econ. 2016, 49, 537-574. [CrossRef]

29. Zou, W.; Zhang, F. The income gap and the accumulation of human capital in rural China. Chin. Soc. Sci. 2006, 26, 67-79.

30. Yan, X.H. Empirical analysis of the relationship between urbanization level and long-term economic growth -Based on panel data from 27 provinces. Economics 2011, 3, 25-28.

31. Xiong, C.; Gao, H. Research on the disharmony between population urbanization and spatial urbanization-Based on the perspective of fiscal decentralization. Res. Political Econ. 2013, 1, 173-185.

32. Kong, X.; Deng, F. An empirical analysis of the population urbanization effect on the economic growth in China. Popul. Econ. 2015, 6, 32-42.

33. Zhou, G.; Luo, S. Higher education input, technological innovation, and economic growth in China. Sustainability 2018, 10, 2615. [CrossRef]

34. Chan, K.W.; Zhang, L. The hukou system and rural-urban migration in China: Processes and changes. China Q. 1999, 160, 818-855. [CrossRef] [PubMed]

35. Chen, Y. The problems of rural education brought by urbanization. Fujian Forum (Humanit. Soc. Sci.) 2007, S1, 237-238.

36. Xu, S.; Law, W.W. Rural education and urbanization: Experiences and struggles in China since the late 1970's. Glob. Educ. Rev. 2015, 2, 78-100.

37. Arnold, M.L. Rural education: A new perspective is needed at the U.S. Department of Education. J. Res. Rural Educ. 2005, 20,1-3.

(C) 2020 by the authors. Licensee MDPI, Basel, Switzerland. This article is an open access article distributed under the terms and conditions of the Creative Commons Attribution (CC BY) license (http://creativecommons.org/licenses/by/4.0/). 